\title{
Molecular characterization of carbapenem-resistant Acinetobacter species in an Irish university hospital: predominance of Acinetobacter genomic species 3
}

\author{
Correspondence \\ B. Crowley \\ bcrowley@stjames.ie
}

Received 10 July 2008

Accepted 9 October 2008

\author{
T. W. Boo, ${ }^{1}$ F. Walsh ${ }^{1}$ and B. Crowley ${ }^{2}$ \\ ${ }^{1}$ Department of Clinical Microbiology, Trinity College, University of Dublin, James's Street, Dublin 8,
Ireland \\ ${ }^{2}$ Central Pathology Laboratory, Department of Microbiology, St James's Hospital, James's Street, \\ Dublin 8, Ireland
}

\begin{abstract}
A 30 month prospective study of Acinetobacter species encountered in the Central Pathology Laboratory of St James's Hospital, Dublin, Ireland, was conducted to investigate the prevalence and molecular epidemiology of carbapenem resistance in such isolates. Acinetobacter genomic species 3 (AG3) was found to be the predominant Acinetobacter species $(45 / 114,39 \%)$ in our institution. A total of $11 \%$ of all Acinetobacter species (12/114) and $22 \%$ of AG3 isolates (10/ 45) were carbapenem resistant. Carbapenem resistance was mediated by Ambler class D $\beta$ lactamase OXA-23 in all 12 isolates, with insertion sequence ISAba1 found upstream of bla OXA23. ISAba1 was also found upstream of bla $a_{A D C-25}$, which encodes the enzyme AmpC, in an Acinetobacter baumannii isolate, and upstream of the aminoglycoside-acetyltransferaseencoding gene aacC2 in three AG3 isolates. Inter-species plasmidic transfer was most likely involved in the emergence and spread of bla institution. The emergence of carbapenem resistance was associated not only with prior carbapenem use but also with the use of other antimicrobial agents, most notably $\beta$-lactam/ $\beta$ lactamase-inhibitor combinations. The study demonstrated the emerging trend of carbapenem resistance in the wider context of the Acinetobacter genus, and reiterated the paramount importance of the prudent use of antimicrobial agents, stringent infection control measures and resistance surveillance of pathogens.
\end{abstract}

\section{INTRODUCTION}

Acinetobacter spp. have become major pathogens in hospital-associated infections, especially in critical care settings such as intensive care units (ICUs) and units for patients with severe burns (Murray \& Hospenthal, 2008; Sunenshine et al., 2007). They can survive in the hospital environment for long periods and have a remarkable propensity to develop resistance to multiple classes of

Abbreviations: AG3, Acinetobacter genomic species 3; CLSI, Clinical and Laboratory Standards Institute; ICU, intensive care unit; $M B L$, metallo $\beta$-lactamase.

The GenBank/EMBL/DDBJ accession numbers for the Acinetobacter sequences reported in this paper are as follows: EU827524 (Acinetobacter genomic species 3 ISAba1/blaoxA-23/ATPase), EU827525 (Acinetobacter johnsonii ISAba1/bla 0 XA-23/ATPase), EU827526 (Acinetobacter baumannii ISAba1/bla OXA-23/ATPase), EU835512 (Acinetobacter baumannii ISAba1/bla ADC-25), EU839488 (Acinetobacter genomic species 3 ISAba1/aacC2), EU872057 (Acinetobacter johnsonnii aacC2).

A table of primer sequences is available as supplementary material with the online version of this paper. antimicrobial agents. As a result, they can cause a variety of infections including ventilator-associated pneumonia and bacteraemia. Carbapenems have been a particularly useful group of antibiotics in the treatment of such infections as they are $\beta$-lactams with the broadest spectra of activity. They are clinically effective against Gram-negative organisms producing Ambler classes A and C extended-spectrum $\beta$-lactamases. However, carbapenem resistance in Acinetobacter has been increasingly reported worldwide, attributable mainly to Ambler class D carbapenemases and class B metallo- $\beta$-lactamases (MBLs) (Poirel \& Nordmann, 2006; Walther-Rasmussen \& Høiby, 2006). This emerging trend is of grave concern given the prospect of a further reduction in therapeutic options for infections by these multi-drug-resistant organisms. Following the emergence of carbapenem-resistant Acinetobacter species in St James's Hospital in 2005 (Boo et al., 2006), a prospective study of Acinetobacter isolates encountered in the Central Pathology Laboratory, St James's Hospital, was conducted to ascertain the clinical epidemiology, molecular mechanisms and genetic regulation of these carbapenem-resistant isolates. 


\section{METHODS}

Collection of Acinetobacter isolates. Isolates were prospectively screened and collected in the Central Pathology Laboratory of St James's Hospital over a 30 month period from May 2005 to October 2007. In cases where there were two or more specimens yielding the same organism in a patient, the first isolate from each patient episode was chosen.

Identification of organisms. Acinetobacter isolates were presumptively identified using the Vitek-2 GNI identification system (bioMérieux). Confirmatory identification and speciation was carried out by PCR and sequencing of the $r p o B$ gene and flanker regions, as described by La Scola et al. (2006). In this study, a 500 bp segment of the $r p o B$ gene, as well as a region of variable size flanking the $r p o B$ and $r p o C$ genes, were selected for PCR and sequencing.

Antimicrobial susceptibility testing. Antimicrobial susceptibility testing was performed using Vitek GNI susceptibility test system (bioMérieux) for the following antimicrobial agents: ampicillin, amoxicillin-clavulanate, piperacillin-tazobactam, cefoxitin, cefotaxime, ceftazidime, cefepime, meropenem, ciprofloxacin, trimethoprim-sulphamethoxazole, gentamicin and amikacin. MICs were determined using Etest strips (bioMérieux) for the above antimicrobial agents, as well as for the following agents: tigecycline, colistin and imipenem. Carbapenem-resistant isolates were also screened phenotypically for the presence of MBL using imipenem versus imipenem +EDTA Etest MIC strips (bioMérieux). Resistance was defined using Clinical and Laboratory Standards Institute (CLSI) breakpoints (CLSI, 2006).

Screening for carbapenem-resistance genes. PCR was performed using primers for Ambler class B $\beta$-lactamase-encoding genes bla $a_{\mathrm{VIM}}, b l a_{\mathrm{IMP}}, b l a_{\mathrm{SPM}}, b l a_{\mathrm{GIM}}$ and bla $a_{\mathrm{SIM}}$ (Castanheira et al., 2004; Lee et al., 2005; Pitout et al., 2005), as well as Ambler class D carbapenemase-encoding genes $b l a_{\mathrm{OXA}-23-\text { like, }}, b l a_{\mathrm{OXA}-24-\text { like }}, b l a_{\mathrm{OXA}-51 \text {-like }}$ and $b l a_{\text {OXA-58 }}$ (Afzal-Shah et al., 2001; Coelho et al., 2006; Héritier et al., 2005) (Supplementary Table S1 available with the online journal). The PCR was carried out in the GeneAmp 9700 PCR system thermal cycler (Applied BioSystems) using a Qiagen PCR core kit (Qiagen) under the conditions specified by the manufacturer.

Screening of other resistance genes. PCR was also performed to screen for other resistance genes that might be present in carbapenem-resistant isolates, including those encoding Ambler class A $\beta$-lactamase-encoding genes $\left(b l a_{\mathrm{TEM}}, b l a_{\mathrm{SHV}}, b l a_{\mathrm{CTX}-\mathrm{M}}, b l a_{\mathrm{VEB}}\right.$ and bla $a_{\mathrm{PER}}$ ) (Hopkins et al., 2006; Naas et al., 2006) and Ambler class $\mathrm{C}$ Acinetobacter-derived cephalosporinase-encoding genes $\left(b l a_{\mathrm{ADC}}\right)$ (Hujer et al., 2005). The presence of integrons was screened using primers specific for class 1 and class 2 integrases (Koeleman et al., 2001). Aminoglycoside resistance was investigated by screening for genes encoding aminoglycoside-modifying enzymes, aacC1, aacC2 and aphA6 (Vila et al., 1999). The primers are shown in Supplementary Table S1 available with the online journal.

Screening for insertion sequence ISAba1. The presence of the ISAba1 insertion sequence, upstream of the resistance genes and in the correct orientation to promote resistance-gene expression, was sought using a forward primer homologous to sequences located within ISAba1 and reverse primers homologous to the respective resistance genes.

Nucleotide sequencing. Sequencing of amplicons in both directions was performed at the Institute of Molecular Medicine, Trinity College, University of Dublin, with the ABI Prism 3130xl analyser (Applied BioSystems) using the BigDye terminator V3.1 cycle sequencing kit (Applied BioSystems) according to the manufacturer's specifications. Sequences were aligned using CLUSTAL W software (www.ebi.ac.uk/Tools/clustalw) and compared with existing GenBank sequences using the BLAST programme (www.ncbi.nih.gov/blast). The sequences of our isolates were submitted to GenBank, National Center for Biotechnology Information (www.ncbi.nih.gov/Genbank).

Epidemiological typing of isolates. Epidemiological typing of carbapenem-resistant isolates was carried out using PFGE following digestion of genomic DNA by restriction endonuclease ApaI as described by Seifert et al. (2005). The PFGE patterns were analysed using BioNumerics software (BioSystematica) according to the criteria described by Tenover et al. (1995).

Plasmid studies. Plasmid extraction of bacterial suspensions was carried out using a plasmid midi kit (Qiagen) according to the manufacturer's specifications. PCR using the plasmid preparations as templates was performed to ascertain whether the carbapenemresistance genes were plasmid borne. PCR of the $r p o B$ gene was also performed using the same plasmid preparations to look for evidence of chromosomal contamination during the extraction procedure. Following gel electrophoresis, DNA from individual plasmid bands was eluted using a gel extraction kit (Qiagen) and used as template for PCR to ascertain the sizes of the plasmids carrying the resistance genes.

Clinical and epidemiological data for the patients. Clinical, epidemiological and demographic data for the patients were obtained from clinical case notes and from the Central Pathology Laboratory surveillance database. Infection was defined as the isolation of the organism from a normally sterile site; or clinical evidence of sepsis originating from a normally non-sterile site where significant colony counts of the organism had been cultured.

\section{RESULTS AND DISCUSSION}

\section{Species identification of Acinetobacter isolates}

A total of 114 Acinetobacter isolates were collected in the Central Pathology Laboratory over the stipulated period. The Vitek-2 GNI identification system identified the isolates (and their numbers) as follow: Acinetobacter baumannii (77), Acinetobacter lwoffii (31), Acinetobacter junii (2), Acinetobacter haemolyticus (4). However, rpoB gene sequencing revealed the distribution of the various species as shown in Table 1. All amplicons had sequence concordance of 98 to $100 \%$ when compared with the respective reference GenBank sequences (La Scola et al., 2006). A total of $39 \%(45 / 114)$ of all isolates were Acinetobacter genomic species 3 (AG3) while A. baumannii constituted $22 \%(25 / 114)$ of the total. The predominance of AG3 over A. baumannii was an unusual finding but such an epidemiology had occasionally been reported in hospitals (Traub \& Bauer, 2000). This study also demonstrated the poor accuracy of the speciation of Acinetobacter species by the Vitek-2 GNI identification system, with $75 \%$ of isolates erroneously speciated. It highlights the need to regard such results as preliminary data. Accurate speciation using molecular methods not only is important in the investigation of outbreaks caused by Acinetobacter species, but also is relevant in epidemiological studies such as this report. 
Table 1. Speciation and meropenem MICs of Acinetobacter isolates collected in the Central Pathology Laboratory, St James's Hospital (May 2005 to October 2007)

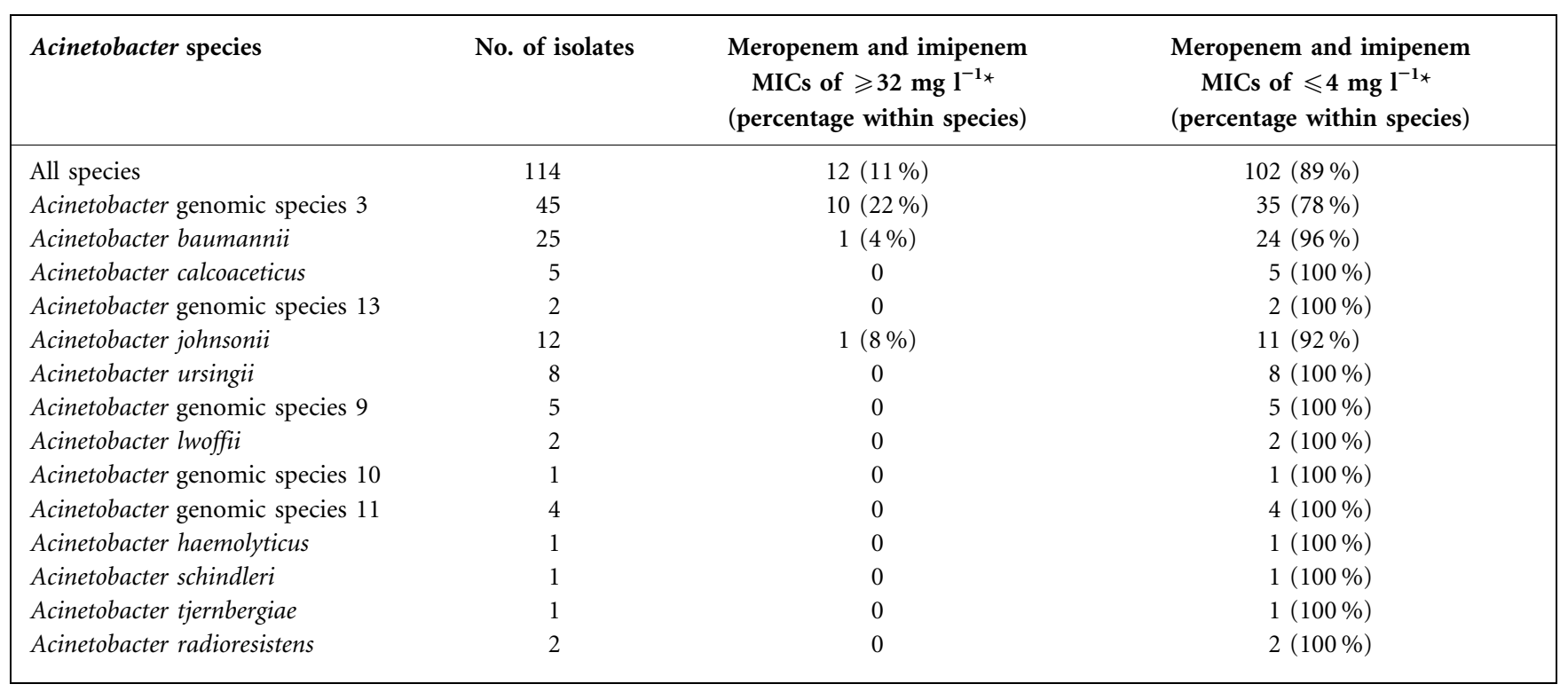

${ }^{\star}$ Based on the Etest method; no isolate had an MIC of 8 or $16 \mathrm{mg} 1^{-1}$.

\section{Antimicrobial susceptibility of carbapenem- resistant isolates}

Vitek-2 MICs corresponded closely with those obtained with the Etest method. Of the 114 isolates, 12 (11\% of the total) were resistant to both meropenem and imipenem (MICs of $\geqslant 32 \mathrm{mg} \mathrm{l}^{-1}$ ) (Table 1). Ten isolates were AG3, while the remaining two were $A$. baumannii and Acinetobacter johnsonii. The remaining 102 isolates were susceptible to both meropenem and imipenem (MICs of $\leqslant 4 \mathrm{mg} \mathrm{l}^{-1}$ ). A significant proportion $(22 \%)$ of the AG3 isolates was thus found to be carbapenem resistant, and to the authors' knowledge, this study is the first report of a carbapenem-resistant A. johnsonii clinical isolate. Worldwide, the overwhelming majority of carbapenemresistant isolates are A. baumannii isolates. AG3 has rarely been reported to be carbapenem resistant (Boo et al., 2006; Marti et al., 2008b). The unusual predominance of AG3 among the carbapenem-resistant isolates in our institution probably reflects the relative distribution of the various Acinetobacter species locally. This study adds to the emerging reports of carbapenem resistance in clinical isolates of Acinetobacter species other than A. baumannii, such as Acinetobacter genomic species 13TU and genomic species 16 (Marti et al., 2008a; Martinovich et al., 2008). Since species such as AG3 and 13TU were also associated with clinically important infections (Traub \& Bauer, 2000), the development of carbapenem resistance in these species is yet another worrisome development in multidrug resistance within the Acinetobacter genus.

The antimicrobial susceptibility results of the 12 isolates can be divided into 4 antibiograms (Table 2). All 12 isolates demonstrated full resistance to ampicillin, amoxicillin- clavulanate, piperacillin-tazobactam, cefoxitin, meropenem, imipenem and ciprofloxacin., while all isolates had colistin MICs of $\leqslant 0.5 \mathrm{mg} \mathrm{l}^{-1}$. Ratios of $\geqslant 8$ with the MBL Etest (imipenem MIC versus imipenem + EDTA MIC) were obtained for the 12 isolates, giving presumptive positive results for MBL. Seven AG3 isolates (antibiogram 1) were susceptible to ceftazidime, aminoglycosides and trimethoprim-sulphamethoxazole, and had intermediate or full resistance to cefotaxime and cefepime. Antibiogram 2 (A. johnsonii) had a similar profile as antibiogram 3 (three remaining AG3 isolates) but with lower cephalosporin MICs and a higher gentamicin MIC. Of note, all AG3 and A. johnsonii isolates had cefepime MICs that were two to eight times higher than those of ceftazidime. The A. baumannii isolate was highly resistant to cephalosporins, trimethoprim-sulphamethoxazole and aminoglycosides (antibiogram 4). All AG3 and A. johnsonii isolates had tigecycline MICs of $\leqslant 0.5 \mathrm{mg} \mathrm{l}^{-1}$, while the A. baumannii isolate had a tigecycline MIC of $2 \mathrm{mg} \mathrm{l}^{-1}$.

\section{Carbapenem-resistance genes and their genetic surroundings}

The resistance genes of the various isolates are summarized in Table 3. PCR was negative for $b l a_{\mathrm{VIM}}, b l a_{\mathrm{IMP}}, b l a_{\mathrm{SPM}}$, $b l a_{\mathrm{GIM}}, b l a_{\mathrm{SIM}}, b l a_{\mathrm{OXA}-24-\text { like }}$ and $b l a_{\mathrm{OXA}-58}$. False-positive results were thus obtained with the MBL Etest, which serves as a reminder that PCR confirmation of such results is still required as OXA carbapenemases can produce falsepositive MBL results (Segal \& Elisha, 2005). To date, there is still no reliable phenotypic method distinguishing MBLs from OXA carbapenemases. 
Table 2. Antimicrobial susceptibility patterns of the carbapenem-resistant isolates

Susceptibility was determined according to CLSI interpretation criteria (CLSI, 2006). I, intermediate; R, Resistant; S, susceptible.

\begin{tabular}{|c|c|c|c|c|}
\hline Antimicrobial agent & $\begin{array}{c}\text { Antibiogram } 1 \\
\text { (MIC value) }\end{array}$ & $\begin{array}{c}\text { Antibiogram } 2 \\
\text { (MIC value) }\end{array}$ & $\begin{array}{c}\text { Antibiogram } 3 \\
\text { (MIC value) }\end{array}$ & $\begin{array}{c}\text { Antibiogram } 4 \\
\text { (MIC value) }\end{array}$ \\
\hline Cefotaxime & $\mathrm{I} / \mathrm{R}\left(32-64 \mathrm{mg} \mathrm{l}^{-1}\right)$ & $\mathrm{I}\left(16 \mathrm{mg} \mathrm{l}^{-1}\right)$ & $\mathrm{R}\left(128-\geqslant 256 \mathrm{mg} \mathrm{l}^{-1}\right)$ & $\mathrm{R}\left(\geqslant 256 \mathrm{mg} \mathrm{l}^{-1}\right)$ \\
\hline Ceftazidime & $\mathrm{S}\left(4-8 \mathrm{mg} \mathrm{l}^{-1}\right)$ & $\mathrm{S}\left(8 \mathrm{mg} \mathrm{l}^{-1}\right)$ & I/R $\left(16-32 \mathrm{mg} \mathrm{l}^{-1}\right)$ & $\mathrm{R}\left(\geqslant 256 \mathrm{mg} \mathrm{l}^{-1}\right)$ \\
\hline Cefepime & $\mathrm{I} / \mathrm{R}\left(16-64 \mathrm{mg} \mathrm{l}^{-1}\right)$ & $\mathrm{R}\left(32 \mathrm{mg} \mathrm{l}^{-1}\right)$ & $\mathrm{R}\left(64-128 \mathrm{mg} \mathrm{l}^{-1}\right)$ & $\mathrm{R}\left(\geqslant 256 \mathrm{mg} \mathrm{l}^{-1}\right)$ \\
\hline Trimethoprim-sulfamethoxazole & $\mathrm{S}\left(\leqslant 1 / 19 \mathrm{mg} \mathrm{l}^{-1}\right)$ & $\mathrm{R}\left(\geqslant 32 / 608 \mathrm{mg} \mathrm{l}^{-1}\right)$ & $\mathrm{R}\left(\geqslant 32 / 608 \mathrm{mg} \mathrm{l}^{-1}\right)$ & $\mathrm{R}\left(\geqslant 32 / 608 \mathrm{mg} \mathrm{l}^{-1}\right)$ \\
\hline Gentamicin & $\mathrm{S}\left(0.25-1 \mathrm{mg} \mathrm{l}^{-1}\right)$ & $\mathrm{R}\left(128 \mathrm{mg} \mathrm{l}^{-1}\right)$ & $\mathrm{R}\left(32 \mathrm{mg} \mathrm{l}^{-1}\right)$ & $\mathrm{R}\left(\geqslant 256 \mathrm{mg} \mathrm{l}^{-1}\right)$ \\
\hline Amikacin & $\mathrm{S}\left(0.5-2 \mathrm{mg} \mathrm{l}^{-1}\right)$ & $\mathrm{S}\left(1 \mathrm{mg} \mathrm{l}^{-1}\right)$ & $\mathrm{S}\left(0.5-2 \mathrm{mg} \mathrm{l}^{-1}\right)$ & $\mathrm{R}\left(\geqslant 256 \mathrm{mg} \mathrm{l}^{-1}\right)$ \\
\hline Types of isolates (no.) & AG3 (7) & A. johnsonii (1) & AG3 (3) & A. baumannii (1) \\
\hline Isolate identifier & $\begin{array}{l}\text { S659, A629, S448, S748, } \\
\text { S165, A594, A616 }\end{array}$ & A868 & A540, A277, A357 & $\mathrm{U} 437$ \\
\hline
\end{tabular}

A. baumannii was positive for both $b l a_{\text {OXA-23-like }}$ and bla $a_{\text {OXA-51-like }}$ genes, while the other 11 isolates were positive for the $b l a_{\text {OXA-23-like gene only. Nucleotide sequencing of }}$

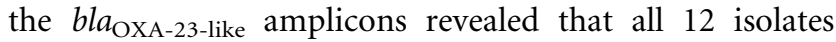
carried the classical $b a_{\text {OXA-23 }}$ gene, which has also been reported in various continents including Europe, Asia and America (Coelho et al., 2006; Corvec et al., 2007; Meric et al., 2008; Valenzuela et al., 2007; Villegas et al., 2007; Zong et al., 2008). In addition, the insertion sequence ISAbal was found immediately upstream of $b l a_{\text {OXA-23 }}$ in all 12 isolates (separated by 17 nucleotides); while the ATPaseencoding gene was found downstream of it. The regions between ISAbal and $b l a_{\mathrm{OXA}-23}$ of all 12 isolates were identical in sequence, as were the regions between $b l a_{\text {OXA-23 }}$ and ATPase-encoding gene (104 nucleotides in length). ISAbal was not present upstream of the $b l a_{\text {OXA-51-like }}$ gene in the $A$. baumannii isolate. Hence the $\beta$-lactamaseencoding gene contributing to carbapenem resistance for all 12 isolates from St James's Hospital was $b l a_{\mathrm{OXA}-23}$, since ISAbal was shown to possess promoter sequences that upregulated expression of the $\beta$-lactamase-encoding genes downstream (Corvec et al., 2007; Héritier et al., 2006). Additional mechanisms of resistance that have not been investigated in this study, such as loss of membrane porins and multidrug efflux pump, may also play important roles in the development of carbapenem resistance (Dupont et al., 2005; Magnet et al., 2001; Siroy et al., 2005).

\section{Other resistance genes}

No Ambler class A $\beta$-lactamase-encoding genes ( $b l a_{\mathrm{TEM}}$, bla $a_{\mathrm{SHV}}, b l a_{\mathrm{CTX}-\mathrm{M}}, b l a_{\mathrm{VEB}}$ and $\left.b l a_{\mathrm{PER}}\right)$ were detected by PCR. The Ambler class C ADC-encoding genes of the AG3 and A. baumannii isolates were sequenced. All 10 AG3 isolates were positive for $b l a_{\mathrm{ADC}-18}(>99 \%$ concordance with GenBank accession number AM283523), while the $A$.

Table 3. Resistance genes of carbapenem-resistant isolates

\begin{tabular}{|c|c|c|c|c|c|}
\hline \multirow[t]{2}{*}{ Isolate identifier } & \multirow[t]{2}{*}{ Species } & \multicolumn{4}{|c|}{ Resistance gene/cassette encoding: } \\
\hline & & OXA & ADC & $\begin{array}{c}\text { Aminoglycoside-modifying } \\
\text { enzymes }\end{array}$ & Class 1 integron \\
\hline A540 & AG3 & ISAba1+OXA-23 & ADC-18 & ISAba1 $+a a c C 2$ & - \\
\hline S659 & AG3 & ISAba1+OXA-23 & ADC-18 & - & - \\
\hline A629 & AG3 & ISAba1+OXA-23 & ADC-18 & - & - \\
\hline S448 & AG3 & ISAba1+OXA-23 & ADC-18 & - & - \\
\hline S748 & AG3 & ISAba1+OXA-23 & ADC-18 & - & - \\
\hline A594 & AG3 & ISAba1+OXA-23 & ADC-18 & - & - \\
\hline A616 & AG3 & ISAba1+OXA-23 & ADC-18 & - & - \\
\hline A277 & AG3 & ISAba1+OXA-23 & ADC-18 & ISAba1+aacC2 & - \\
\hline A357 & AG3 & ISAba1+OXA-23 & ADC-18 & ISAba1+aacC2 & - \\
\hline S165 & AG3 & ISAba1+OXA-23 & ADC-18 & - & - \\
\hline $\mathrm{U} 437$ & A. baumannii & $\begin{array}{l}\text { OXA-51 group; } \\
\text { ISAba1 + OXA-23 }\end{array}$ & $\mathrm{ISA} b a 1+\mathrm{ADC}-25$ & aphA6 & + \\
\hline A868 & A. johnsonii & ISAba1 + OXA-23 & $?^{*}$ & aacC2 & - \\
\hline
\end{tabular}

+ , Present; -, absent

${ }^{\star}$ PCR product not obtained with study primers. 
baumannii isolate was positive for $b l a_{\mathrm{ADC}-25}(>99 \%$ concordance with GenBank accession number EF016355). We were unable to obtain an amplicon for the A. johnsonii isolate with the $b l a_{\mathrm{ADC}}$ primers used in this study. Since OXA-23 has little activity on third and fourth generation cephalosporins, the ADC enzymes are responsible for hydrolysing these $\beta$-lactams. The cephalosporin susceptibility profiles (where cefepime MICs were higher than ceftazidime MICs) of the AG3 isolates were different from those of most Ambler class C enzymes of other Gramnegative organisms as well as some ADC enzymes such as ADC-7 (Hujer et al., 2005). This suggests that different ADC subtypes may have different affinities for the various cephalosporins. ISAbal was found upstream of the $A$. baumannii $b l a_{\mathrm{ADC}-25}$, but not of the $b l a_{\mathrm{ADC}-18}$ of the AG3 isolates.

The A. baumannii isolate was the only isolate to possess a class 1 integron and also carried the aminoglycoside phosphotransferase-encoding gene aphA6 (99\% concordance with GenBank accession number X07753), which accounted for the resistance to amikacin as well as gentamicin. The three gentamicin-resistant AG3 isolates were positive for the aminoglycoside-acetyltransferaseencoding gene aacC2 (100\% concordance with GenBank accession number AY138987). ISAba1 was found upstream of the aacC2 gene in all three isolates, with a truncated $3^{\prime}$ end of insertion sequence IS1133 found between ISAba1 and aacC2 (GenBank accession number EU839488). The aacC2 gene was also found in the $A$. johnsonii isolate, but without ISAbal upstream of it. This study demonstrates the role of ISAba1 in the regulation of various $\beta$-lactamaseencoding genes in $A$. baumannii and also in other Acinetobacter species. Not only was it found upstream of the $b l a_{\mathrm{OXA}-23}$ of various species, but was also found upstream of the $b l a_{\mathrm{ADC}-25}$ gene in $A$. baumannii. Upregulation of $b l a_{\mathrm{ADC}-25}$ was the most likely explanation for the higher cephalosporin MICs of A. baumannii in contrast to those of the AG3 isolates, which did not possess ISAbal upstream of $b l a_{\mathrm{ADC}-18}$. The role of ISAba1 in the regulation of genes encoding aminoglycoside-modifying enzymes was less clear. Gentamicin MICs of AG3 isolates possessing ISAba1 upstream of aacC2 were lower than MICs observed in A. baumannii and A. johnsonii where ISAbal was absent upstream of aphA6 and aacC2, respectively. This would suggest that ISAba1 did not upregulate the expression of such genes. Other mechanisms of resistance may also have contributed to aminoglycoside resistance in our isolates. In particular, overexpression of multidrug efflux pumps such as AdeABC confers resistance to aminoglycosides and several other classes of antimicrobial agents in A. baumannii (Magnet et al., 2001).

\section{Epidemiological typing and plasmid studies}

The ten AG3 isolates were divided into two genotype groups according to their PFGE banding patterns. Group 1 contained seven isolates S659, A629, A616, A594, S448,
S748 and S165 that had $\geqslant 85 \%$ similarity and therefore were closely related. Within this group isolates S448 and S748 were clonally related with identical PFGE patterns. In group 2, isolates A540, A277 and A357 had indistinguishable PFGE patterns and hence were clonal. The two groups had $<70 \%$ similarity to each other and therefore were not related. PFGE groups 1 and 2 corresponded closely with antibiogram patterns 1 and 3, respectively (Table 2).

Four isolates [A. baumannii (U437), A. johnsonii (A868), and representative AG3 isolates of the two PFGE clusters ([A357 and S448)] were used for the plasmid studies. PCRs of plasmid preparations for all four isolates were positive for $b l a_{\mathrm{OXA}-23}$, while the PCR for the $r p o B$ gene was negative for all four isolates. This indicated that the plasmid preparations were free of chromosomal contamination and that $b l a_{\mathrm{OXA}-23}$ was plasmid borne for the four isolates. Following gel electrophoresis of the plasmid preparations, A. johnsonii and AG3 (isolate A357) demonstrated two plasmid bands of about $40 \mathrm{MDa}$ and about $95 \mathrm{MDa}$. No bands could be visualized for $A$. baumannii and the other AG3 isolate (S448), which might be the result of lower copy numbers within the preparations. The plasmid bands from the former two isolates were eluted and PCR was positive for bla $a_{\mathrm{OXA}-23}$ for the 40 $\mathrm{MDa}$ bands in both isolates, implying that $b a_{\text {OXA-23 }}$ was carried on the $40 \mathrm{MDa}$ plasmids in these isolates. Thus, while PFGE demonstrated the two different clones and closely related isolates of carbapenem-resistant AG3, plasmid studies also revealed that plasmidic transfer of $b a_{\mathrm{OXA}-23}$ between different Acinetobacter species (at least between AG3 and A. johnsonii) most probably occurred in our institution as well. This is further supported by the similarities of the genetic surroundings of $b l a_{\text {OXA-23 }}$ among the different species. This presents a worrying prospect that multiple mechanisms, such as inter-species plasmidic transfer and to a lesser degree, clonal spread, are likely to be involved in promoting the spread of carbapenem resistance within the Acinetobacter population in our hospital.

\section{Clinical and epidemiological data}

The microbiological data of the isolates, and the clinical and demographic data of the respective patients are summarized in Table 4. Carbapenem-resistant Acinetobacter were isolated from a variety of specimens including sputum, urine, swabs and third-space fluids. There was a male-to-female patient ratio of $2: 1$ and most were hospital in-patients for longer than 2 weeks when culture-positive. The majority of the patients were infected with the organisms and most had significant co-morbidities and/ or major surgery. Epidemiologically, the patients were located in a wide variety of settings, not just the criticalcare settings. Most notably, the A. baumannii isolate was isolated from a patient from the community, although it was unclear whether there was a history of prior 
Table 4. Clinical data for patients with carbapenem-resistant Acinetobacter isolates

\begin{tabular}{|c|c|c|c|c|c|c|c|c|c|c|}
\hline \multirow[t]{2}{*}{ Isolate } & \multicolumn{3}{|c|}{ Specimen data } & \multicolumn{7}{|c|}{ Patient data } \\
\hline & Organism & $\begin{array}{c}\text { Date of } \\
\text { isolation } \\
\text { (month/ } \\
\text { year) }\end{array}$ & $\begin{array}{l}\text { Specimen } \\
\text { type }\end{array}$ & $\begin{array}{c}\text { Age } \\
\text { (years) }\end{array}$ & Sex & Location & $\begin{array}{l}\text { Duration } \\
\text { of stay in } \\
\text { hospital }^{\star}\end{array}$ & $\begin{array}{l}\text { Infection } \\
\text { status of } \\
\text { organism }\end{array}$ & $\begin{array}{l}\text { Recent anti-Gram- } \\
\text { negative antibiotics }\end{array}$ & Underlying condition \\
\hline S659 & AG3 & 05/05 & Sputum & 49 & $\mathrm{M}$ & ICU & 19 days & Colonized & Mer, Cip & Crohn's disease; pancolectomy \\
\hline A540 & AG3 & 08/05 & Biliary fluid & 62 & $\mathrm{~F}$ & Surgical ward A & 37 days & Infected & Ptz, Cip & Pancreatic carcinoma; gastrojejunostomy \\
\hline A629 & AG3 & 03/06 & Biliary fluid & 71 & $\mathrm{~F}$ & Surgical ward B & 15 days & Infected & Aug, Cip & Pancreatic carcinoma; biliary tract surgery \\
\hline A868 & A. johnsonii & $05 / 06$ & Chest drain fluid & 44 & M & Medical ward A & 61 days & Infected & Cip & Liver failure, recurrent empyema \\
\hline A616 & AG3 & $06 / 06$ & Wound swab & 44 & M & ICU & 29 days & Infected & Ptz, Cip & Severe trauma, rhabdomyolysis, viral hepatitis \\
\hline A594 & AG3 & 07/06 & Leg wound & 49 & M & Surgical ward C & 22 days & Colonized & Pen, Clox & Lower limb cellulitis \\
\hline S448 & AG3 & $08 / 06$ & Sputum & 56 & $\mathrm{~F}$ & Oncology ward & 58 days & Infected & Mer, Cip & Oesophageal carcinoma, diabetes mellitus \\
\hline S748 & AG3 & 09/06 & Sputum & 73 & $\mathrm{M}$ & Oncology ward & 5 days $\dagger$ & Colonized & Aug, Cip & Lung carcinoma \\
\hline A357 & AG3 & $10 / 06$ & Leg swab & 62 & M & ICU & 24 days & Colonized & Ptz, Cip & Abdominal surgery, cardiovascular disease \\
\hline A277 & AG3 & $12 / 06$ & Leg swab & 57 & $\mathrm{M}$ & Surgical ward D & 33 days & Colonized & Cip & Major trauma and surgery \\
\hline S165 & AG3 & $05 / 07$ & Sputum & 64 & M & Medical ward B & 27 days & Infected & Ptz, Cip & Wegener's granulomatosus, diabetes mellitus \\
\hline U437 & A. baumannii & $08 / 07$ & Urine & 71 & $\mathrm{~F}$ & Community & $\mathrm{NA}$ & Infected & Data unavailable & Data unavailable \\
\hline
\end{tabular}

Aug, Amoxicillin-clavulanate; Cip, ciprofloxacin; Mer, meropenem; NA, not applicable; Pen, penicillin; Ptz, piperacillin-tazobactam.

${ }^{*}$ Duration from time of admission to the time of organism isolation in the current patient episode.

$\dagger$ Transferred from another hospital. 
hospitalization in the patient. However, there was also some degree of clonal persistence within the institution. AG3 isolates S448 and S748 were isolated in the oncology ward a month apart; while A357 and A277 were isolated 2 months apart in the ICU and surgical ward, respectively, although the patient with isolate A277 had been in the ICU prior to transfer to the surgical ward (ward transfer data are not included in Table 4). Nonetheless, the sporadic nature and different settings for most of the isolates that emerged, together with the findings that different species and clones were involved, would suggest that there was a reservoir of carbapenem-resistant Acinetobacter isolates within the patient population served by the hospital. These organisms might then have manifested following antimicrobial therapy.

Of the 11 patients for whom there were data on antimicrobial therapy prior to the isolation of the organisms, only 2 had prior meropenem treatment. Six had prior therapy with $\beta$-lactam/ $\beta$-lactamase-inhibitor combinations. This raises the possibility of co-selection of carbapenem-resistant isolates by these antimicrobial agents through the acquisition of OXA carbapenemases, since these enzymes possess greater activity against these agents (as well as the carbapenems) than the Ambler class C Acinetobacter-derived cephalosporinases. As ten patients had prior therapy with ciprofloxacin, it may also have a role in selecting out quinolone-resistant isolates concomitantly carrying the OXA-carbapenemase-encoding genes or isolates overexpressing multidrug efflux pumps with resistance to multiple classes of antimicrobial agents. These observations emphasize the importance of the prudent use of all antimicrobial agents, as non-carbapenem agents may have a role in promoting the emergence of carbapenem-resistant Acinetobacter isolates.

There are now mounting data to suggest that the presence of Acinetobacter can contribute adversely to the prognosis of patients, especially in the presence of significant comorbidities (Grupper et al., 2007; Murray \& Hospenthal, 2008), and multidrug resistance in such isolates is associated with increased mortality and prolonged hospitalization (Lee et al., 2007; Sunenshine et al., 2007). Furthermore, since carbapenems are frequently used for the treatment of such multidrug-resistant Acinetobacter infections, carbapenem resistance can further contribute to mortality as a result of discordant empirical therapy (Kwon et al., 2007). In view of such findings, there is now an even greater urgency for resistance surveillance of such organisms as well as the prudent use of antimicrobial agents.

\section{ACKNOWLEDGEMENTS}

We would like to thank the microbiology staff at St James's Hospital for their help in the collection of isolates. Fiona Walsh was supported by a fellowship grant from the Health Research Board, Ireland. Part of the above data was presented at the 18th European Congress of Clinical Microbiology and Infectious Diseases meeting, Barcelona, Spain (19-22 April 2008), as poster P1500.

\section{REFERENCES}

Afzal-Shah, M., Woodford, N. \& Livermore, D. M. (2001). Characterization of OXA-25, OXA-26 and OXA-27, molecular class D $\beta$-lactamases associated with carbapenem resistance in clinical isolates of Acinetobacter baumannii. Antimicrob Agents Chemother 45, 583-588.

Boo, T. W., Walsh, F. \& Crowley, B. (2006). First report of OXA-23 carbapenemase in clinical isolates of Acinetobacter species in the Irish Republic. J Antimicrob Chemother 58, 1101-1102.

Castanheira, M., Toleman, M. A., Jones, R. N., Schmidt, F. J. \& Walsh, T. R. (2004). Molecular characterisation of a $\beta$-lactamase gene, $b l a_{\mathrm{GIM}}$ ${ }_{1}$, encoding a new subclass of metallo- $\beta$-lactamase. Antimicrob Agents Chemother 48, 4654-4661.

CLSI (2006). Performance Standards for Antimicrobial Susceptibility Testing, supplement M100-S16. Wayne, PA: Clinical and Laboratory Standards Institute.

Coelho, J. M., Turton, J. F., Kaufmann, M. E., Glover, J., Woodford, N., Warner, M., Palepou, M. F., Pike, R., Pitt, T. L. \& other authors (2006). Occurrence of carbapenem-resistant Acinetobacter baumannii clones at multiple hospitals in London and southeast England. J Clin Microbiol 44, 3623-3627.

Corvec, S., Poirel, L., Naas, T., Drugeon, H. \& Nordmann, P. (2007). Genetics and expression of the carbapenem-hydrolysing oxacillinase

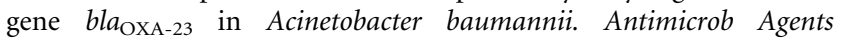
Chemother 51, 1530-1533.

Dupont, M., Pagès, J. M., Lafitte, D., Siroy, A. \& Bollet, C. (2005). Identification of an OprD homologue in Acinetobacter baumannii. $J$ Proteome Res 4, 2386-2390.

Grupper, M., Sprecher, H., Mashiach, T. \& Finkelstein, R. (2007). Attributable mortality of nosocomial Acinetobacter bacteremia. Infect Control Hosp Epidemiol 28, 293-298.

Héritier, C., Dubouix, A., Poirel, L., Marty, N. \& Nordmann, P. (2005). A nosocomial outbreak of Acinetobacter baumannii isolates expressing the carbapenem-hydrolysing oxacillinase OXA-58. I Antimicrob Chemother 55, 115-118.

Héritier, C., Poirel, L. \& Nordmann, P. (2006). Cephalosporinase overexpression resulting from insertion of ISAbal in Acinetobacter baumannii. Clin Microbiol Infect 12, 123-130.

Hopkins, K. L., Deheer-Graham, A., Batchelor, M. J., Liebana, E. \& Threlfall, E. J. (2006). Novel plasmid-mediated CTX-M-8 subgroup extended-spectrum $\beta$-lactamase (CTX-M-40) isolated in the UK. Int $J$ Antimicrob Agents 27, 572-575.

Hujer, K. M., Hamza, N. S., Hujer, A. M., Perez, F., Helfand, M. S., Bethel, C. R., Thomson, J. M., Anderson, V. E., Barlow, M. \& other authors (2005). Identification of a new allelic variant of the Acinetobacter baumannii cephalosporinase, ADC-7 $\beta$-lactamase: defining a unique family of class C enzymes. Antimicrob Agents Chemother 49, 2941-2948.

Koeleman, J. G., Stoof, J., van der Bijl, M. W., VandenbrouckeGrauls, C. M. \& Savelkoul, P. H. (2001). Identification of epidemic strains of Acinetobacter baumannii by integrase gene PCR. J Clin Microbiol 39, 8-13.

Kwon, K. T., Oh, W. S., Song, J. H., Chang, H. H., Jung, S. I., Kim, S. W., Ryu, S. Y., Heo, S. T., Jung, D. S. \& other authors (2007). Impact of imipenem resistance on mortality in patients with Acinetobacter bacteraemia. J Antimicrob Chemother 59, 525-530.

La Scola, B., Gundi, V. A., Khamis, A. \& Raoult, D. (2006). Sequencing of the $r p o B$ gene and flanking spacers for molecular identification of Acinetobacter species. J Clin Microbiol 44, 827-832.

Lee, K., Yum, J. H., Yong, D., Lee, H. M., Kim, H. D., Docquier, J. D., Rossolini, G. M. \& Chong, Y. (2005). Novel acquired metallo- $\beta$ - 
lactamase gene, $b l a_{\mathrm{SIM}-1}$, in a class 1 integron from Acinetobacter baumannii clinical isolates from Korea. Antimicrob Agents Chemother 49, 4485-4491.

Lee, N. Y., Lee, H. C., Ko, N. Y., Chang, C. M., Shih, H. I., Wu, C. J. \& Ko, W. C. (2007). Clinical and economic impact of multidrug resistance in nosocomial Acinetobacter baumannii bacteremia. Infect Control Hosp Epidemiol 28, 713-719.

Magnet, S., Courvalin, P. \& Lambert, T. (2001). Resistancenodulation-cell division-type efflux pump involved in aminoglycoside resistance in Acinetobacter baumannii strain BM4454. Antimicrob Agents Chemother 45, 3375-3380.

Marti, S., Sánchez-Céspedes, J., Blasco, M. D., Alba, V. \& Vila, J. (2008a). Presence of the carbapenem-hydrolyzing oxacillinase OXA58 in an Acinetobacter phenon 6/ct13TU clinical isolate. In Abstracts of the 18th European Congress of Clinical Microbiology and Infectious Diseases, Barcelona, Spain, abstract P1512. Basel: European Society of Clinical Microbiology and Infectious Diseases.

Marti, S., Sánchez-Céspedes, J., Blasco, M. D., Ruiz, M., Espinal, P., Alba, V., Fernández-Cuenca, F., Pascual, A. \& Vila, J. (2008b). Characterization of the carbapenem-hydrolyzing oxacillinase OXA-58 in an Acinetobacter genospecies 3 clinical isolate. Antimicrob Agents Chemother 52, 2955-2958.

Martinovich, A., Shevchenko, O., Edelstein, M. \& Kozlov, R. (2008). Assessment of carbapenem resistance and presence of acquired carbapenemases in Russian nosocomial isolates of Acinetobacter spp. In Abstracts of the 18th European Congress of Clinical Microbiology and Infectious Diseases, Barcelona, Spain, abstract P1505. Basel: European Society of Clinical Microbiology and Infectious Diseases.

Meric, M., Kasap, M., Gacar, G., Budak, F., Dundar, D., Kolayli, F., Eroglu, C. \& Vahaboglu, H. (2008). Emergence and spread of carbapenem-resistant Acinetobacter baumannii in a tertiary care hospital in Turkey. FEMS Microbiol Lett 282, 214-218.

Murray, C. K. \& Hospenthal, D. R. (2008). Acinetobacter infection in the ICU. Crit Care Clin 24, 237-248.

Naas, T., Bogaerts, P., Bauraing, C., Degheldre, Y., Glupczynski, Y. \& Nordmann, P. (2006). Emergence of PER and VEB extendedspectrum $\beta$-lactamases in Acinetobacter baumannii in Belgium. J Antimicrob Chemother 58, 178-182.

Pitout, J. D., Gregson, D. B., Poirel, L., McClure, J. A., Le, P. \& Church, D. L. (2005). Detection of Pseudomonas aeruginosa producing metallo$\beta$-lactamases in a large centralized laboratory. J Clin Microbiol 43, 3129-3135.

Poirel, L. \& Nordmann, P. (2006). Carbapenem resistance in Acinetobacter baumannii: mechanisms and epidemiology. Clin Microbiol Infect 12, 826-836.
Segal, H. \& Elisha, B. G. (2005). Use of Etest MBL strips for the detection of carbapenemases in Acinetobacter baumannii. J Antimicrob Chemother 56, 598.

Seifert, H., Dolzani, L., Bressan, R., van der Reijden, T., van Strijen, B., Stefanik, D., Heersma, H. \& Dijkshoorn, L. (2005). Standardization and interlaboratory reproducibility assessment of pulsed-field gel electrophoresis-generated fingerprints of Acinetobacter baumannii. J Clin Microbiol 43, 4328-4335.

Siroy, A., Molle, V., Lemaître-Guillier, C., Vallenet, D., Pestel-Caron, M., Cozzone, A. J., Jouenne, T. \& Dé, E. (2005). Channel formation by CarO, the carbapenem resistance-associated outer membrane protein of Acinetobacter baumannii. Antimicrob Agents Chemother 49, 4876-4883.

Sunenshine, R. H., Wright, M. O., Maragakis, L. L., Harris, A. D., Song, X., Hebden, J., Cosgrove, S. E., Anderson, A., Carnell, J. \& other authors (2007). Multidrug-resistant Acinetobacter infection mortality rate and length of hospitalization. Emerg Infect Dis 13, 97-103.

Tenover, F. C., Arbeit, R. D., Goering, R. V., Mickelsen, P. A., Murray, B. E., Persing, D. H. \& Swaminathan, B. (1995). Interpreting chromosomal DNA restriction patterns produced by pulsed-field gel electrophoresis: criteria for bacterial strain typing. J Clin Microbiol 33, 2233-2239.

Traub, W. H. \& Bauer, D. (2000). Surveillance of nosocomial crossinfections due to three Acinetobacter genospecies (Acinetobacter baumannii, genospecies 3 and genospecies 13) during a 10-year observation period: serotyping, macrorestriction analysis of genomic DNA and antibiotic susceptibilities. Chemotherapy 46, 282-292.

Valenzuela, J. K., Thomas, L., Patridge, S. R., van der Reijden, T., Dijkshoorn, L. \& Iredell, J. (2007). Horizontal gene transfer in a polyclonal outbreak of carbapenem-resistant Acinetobacter baumannii. J Clin Microbiol 45, 453-460.

Vila, J., Ruiz, J., Navia, M., Becerril, B., Garcia, I., Perea, S., LopezHernandez, I., Alamo, I., Ballester, F. \& other authors (1999). Spread of amikacin resistance in Acinetobacter baumannii strains isolated in Spain due to an epidemic strain. J Clin Microbiol 37, 758-761.

Villegas, M. V., Kattan, J. N., Correa, A., Lolans, K., Guzman, A. M., Woodford, N., Livermore, D. \& Quinn, J. P. (2007). Dissemination of Acinetobacter baumannii clones with OXA-23 carbapenemase in Colombian hospitals. Antimicrob Agents Chemother 51, 2001-2004.

Walther-Rasmussen, J. \& Høiby, N. (2006). OXA-type carbapenemases. J Antimicrob Chemother 57, 373-383.

Zong, Z., Lü, X., Valenzuela, J. K., Patridge, S. R. \& Iredell, J. (2008). An outbreak of carbapenem-resistant Acinetobacter baumannii producing OXA-23 carbapenemase in western China. Int $J$ Antimicrob Agents 31, 50-64. 